\title{
Keunikan Rumah Tradisional Jepang Minka
}

\author{
Budi Mulyadi \\ Universitas Diponegoro \\ budi.mulyadi09@gmail.com
}

\begin{abstract}
Abstrak
Penelitian ini berjudul Keunikan Rumah Tradisional Jepang Minka. Tujuan utama penelitian ini untuk mengetahui seluk beluk rumah tradisional Jepang yang disebut minka serta mengetahui keunikannya. Penelitian ini merupakan jenis penelitian kombinasi antara penelitian studi pustaka dengan penelitian lapangan. Metode pengumpulan data yang digunakan dalam penelitian ini adalah meliputi observasi, klasifikasi, analisa, interpretasi sintesa dan deskripsi. Dari hasil penelitian secara garis besar dapat digambarkan bahwa rumah tradisional minka mempunyai sejarah yang sangat panjang dalam perkembangannya serta memiliki keunikan yang menggambarkan kebudayaan Jepang yang pekat dengan unsur alam dan unsur religi.
\end{abstract}

Kata kunci : minka; keunikan; tradisional; rumah

\begin{abstract}
(Title: The uniqueness of Japanese traditional house minka). The main goal of this research is to know everything about the Japanese traditional house minka and it's uniqueness. This research is a combination of library research and field research. The step method used in this research is observation, classification, analysis, interpretation and description. From the result of this paper, in general, can be described that the Japanese traditional house minka has a long story of development and has a uniqueness which describes the Japanese culture which is concentrated with natural and religious elements.
\end{abstract}

Keywords : minka; uniquenese;traditional; house

\section{PENDAHULUAN}

Setiap negara mempunyai ciri khas dalam arsitektur rumah baik rumah tradisional maupun rumah modern. Arsitektur rumah tersebut menggambarkan adat tradisi serta budaya hidup sehari-hari dari masyarakat setempat. Arsitektur juga menyesuaikan dengan kondisi geografis, cuaca serta lingkungan di sekitarnya.

Jepang sebagai negara yang kaya dengan adat istiadat dan kebudayaan mempunyai rumah tradisional yang disebut dengan minka. Minka merupakan sebutan untuk rumah tradisional Jepang dan merupakan hunian untuk rakyat biasa khusunya para petani. Rumah-rumah ini sudah ada sebelum akhir tahun 1800 an dan bisa ditemukan di seluruh wilayah Jepang dan mempunyai ciri khas yang berbeda dari masing-masing daerah.

Sebagai rumah tradisional Jepang, minka mempunyai konsep yang kuat dengan sentuhan alam. Rumah tradisional Jepang mempunyai arsitek yang bisa dilihat sebagai satu kesatuan utuh dari cara pikir dan pandangan masyarakat Jepang terhadap lingkungan alam sekitarnya. Masyarakat tradisional Jepang pada umumnya adalah masyarakat petani yang berpusat pada aktifitas yang berhubungan dengan menanam padi. Sikap kerja sama dan harmoni berkembang antara 
Kiryoku, Volume 3 No 42019

e-ISSN: 2581-0960 p-ISSN: 2599-0497

Tersedia online di http://ejournal.undip.ac.id/index.php/kiryoku

masyarakat Jepang dengan lingkungan alam yang mengitarinya. Mereka tidak berusaha untuk memunculkan sikap melawan atau tunduk terhadap alam tetapi mereka berusaha menyesuaikan diri dengan alam sekitarnya. Hal ini bisa dilihat dari arsitektur rumah tradisional Jepang dimana adaptasi dengan alam menjadi fondasi utama dalam penciptaannya. Rumah tradisisonal Jepang dibangun menyesuaikan diri dengan lingkungan alam, iklim dan kondisi geografi daerah sekitar ( Nihon Jiten, 1998: 622).

Setiap jenis bangunan di dunia ini mempunyai ciri khas masing-masing. Begitu pula dengan rumah tradisional Jepang minka. Ciri khas inilah yang menjadi keunikan dan daya tarik dari rumah minka. Selama ini orang-orang di seluruh dunia menegetahui sejumlah kebudayaan unik drai Jepang seperti budaya melipat kertas origami, upacara minum teh Jepang chanoyu, seni merangkai bunga ikebana, budaya kuliner Jepang seperti sushi dan sashimi. Ternyata keunikan dan kekhasan budaya Jepang juga bisa dilihat dari seni arsitektur rumah tradisional minka. Diharapkan dengan ditulisnya paper tentang rumah tradisional Jepang minka ini orang-orang akan menjadi tahu dan paham bahwa negara Jepang juga mempunyai budaya yang sangat menarik rumah tradisional yang didalamnya terkandung filosofi yang mencerminkan kearifan budaya lokal mereka.

Untuk mengetahui lebih jauh tentang rumah tradisional minka Jepang ini dilakukan penelitian dengan rumusan masalah yaitu apa keunikan rumah tradisional Jepang dilihat dari segi arsitekturnya serta elemen-elemen khasnya.

Adapun tujuan dari penelitian ini adalah untuk mendeskripsikan keunikan rumah tradisional minka Jepang dilihat dari arsitekturnya serta dari elemen-elemen pendukungnya.

\section{METODE PENELITIAN}

Penelitian ini merupakan penelitian gabungan antara penelitian studi pustaka dengan penelitian lapangan pada saat penulis mendapat kesempatan training ke Jepang Studi pustaka digunakan untuk membuat analisa terhadap masalah yang dikaji. Sedangkan penelitian lapangan dilaksanakan untuk mendapatkan data primer dari orang Berikut ini beberapa langkah metode yang dipergunakan

1. Observasi: metode ini digunakan untuk mendapatkan gambaran kehidupan orang dan masyarakat Jepang. Gambaran yang diperoleh merupakan bahan /data primer yang akan ditelaah.

2. Klasifikasi: setelah diperoleh bahan yang cukup dilakukan klasifikasi bahan baik dari segi urgenitas maupun dari segi jenis bahan/data.

3. Analisa: dilakukan analisa dilakukan atas bahan yang sudah diperoleh dan diperkuat bahan/informasi dari buku yang sudah ada.

4. Interpretasi: metode ini digunakan dengan melakukan interpretasi untuk mendapatkan pemahamnan yang tepat terhadap bahan kajian, untuk mendapatkan ide-ide dasar dari bahan kajian, dan gambaran bagaimana bentuk penerapannya secara aktual

5. Sintesa: dari hasil kajian beberapa aspek yang sudah diteliti dan dikaji dengan menguunakan logika deduktif diperoleh siatu sintesa. Sintesa ini merupakan suatu sebagai kesimpulan yang menjawab permasalahan yang diajukan

6. Deskripsi: semua bahan penelitian, kajian ilmiah, dan ujicoba penerapan , sampai pada kesimpulan akhir dideskripsikan dengan mempertahankankan prinsip koherensi. 


\section{PEMBAHASAN}

\subsection{Sejarah Minka}

Diperkirakan Rumah tradisional Minka sudah dibangun oleh orang Jepang sebelum akhir tahun 1800. Rumah-rumah tersebut dapat ditemukan di seluruh wilayah di Jepang dengan ciri khas masing-masing dari daerah tersebut.

Arsitek rumah minka dipengaruhi oleh tiga jenis gaya arsitek rumah yang berevolusi pada masa periode Heian yaitu shinden Zukuri, Shoin Zukuri, dan Sukiya Zukuri.

\subsection{Jenis Rumah Minka berdasarkan}

Wilayah

Minka memiliki keanekaragaman gaya arsitektur bangunan berdasarkan letak geografis sehingga setiap daerah di Jepang memiliki gaya bangunan yang khas.Secara garis besar rumah minka di Jepang dibagi ke dalam dua jenis wilayah yaitu minka di Jepang Utara dan Minka di Jepang Selatan. Berikut penjelasannya

\section{Minka di Jepang Utara}

Daerah utara Jepang merupakan daerah yang beriklim yang sangat dingin di musim dingin dengan curahan salju yang melimpah setiap tahunnya sehingga arsitek rumah minka disesuaikan dengan kondisi iklim tersebut. Ciri khas dari rumah minka di Jepang utara adalah dibangunnya bumbungan terjal beratap jerami serta jendela kecil yang hanya ada dibubungan tersebut. Bumbungan terjal dibangun agar salju tidak menumpuk di atap rumah, hal ini merupakan penyesuaian dengan iklim di Jepang Utara yang mempunyai musim dingin yang panjang dan curah salju yang banyak. Berikut adalah gambar rumah minka yang ada di Jepang Utara.

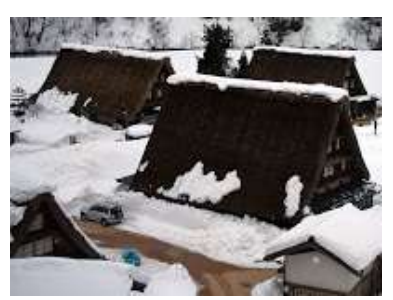

Gambar 1. Rumah minka Jepang Utara

\section{Minka di Jepang Selatan}

Wilayah Jepang bagian Selatan tidak memiliki musim dingin yang panjang serta curah salju sebanyak di wilayah Utara sehingga arsitek rumah Minka di Selatan berbeda dengan yang di Utara. Rumah minka di daerah selatan pada umumnya terdiri dari sekelompok rumah yang relatif lebih kecil, rendah dengan lantai yang ditinggikan agar memperoleh ventilasi yang maksimal dan mengurangi bahaya tiupan angin taifun. Rumah ini dirancang untuk meredam goncangan gempa. Wilayah Selatan Jepang sering dilanda taifun dan gempa bumi sehingga arsitek rumah minka di wilayah Selatan disesuaikan dengan kondisi alamnya. Rumah minka di wilyah selatan Jepang banyak yang buat panggung dengan alasan keamana pada saat terjadi gempa bumi.

Berikut deskripsi rumah panggung minka di wilayah Selatan Jepang

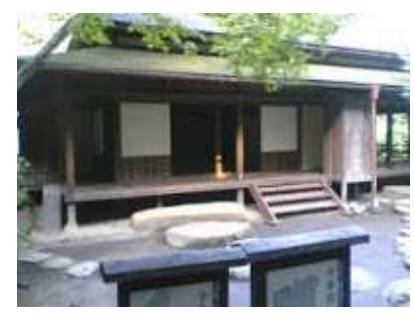

Gambar 2

Rumah minka Jepang Selatan

2.3. Jenis rumah Minka berdasarkan tipenya.

Berdasarkan tipenya secara umum runah minka dibagi dua jenis. 
Kiryoku, Volume 3 No 42019

e-ISSN: 2581-0960 p-ISSN: 2599-0497

Tersedia online di http://ejournal.undip.ac.id/index.php/kiryoku

1. Nouka ( rumah petani)

Tipe rumah petani Jepang yang disebut dengan Nouka ini mempunyai ciri khas pada denahnya dimana denah standar rumah nouka ini mempunyai empat ruang disamping ruang utama yang disebut dengan douma. Pengaturan empat ruang ini disebut dengan yamadori (pengaturan empat ruang). Di rumah nouka ini terdapat pintu kayu sorong besar yang disebut dengan odo yang berfungsi sebagai pintu masuk ruang utama. Pintu ini merupakan pintu utama untuk memasuki rumah petani. Di dalam rumah nouka ini juga terdapat douma yang berfungsi sebagai ruang utama. Douma sering digunakan untuk melakukan aktifitas yang berhubungan dengan pertanian juga sering digunakan untuk memasak sehingga di dalam douma ini terdapat oven yang terbuat dari tanah juga tempat mencuci yang terbuat dari kayu yang dibangun di belakang douma Selain itu di dalam douma juga dibangun perapian yang berukuran satu meter persegi. Di perapian ini kayu dibakar untuk menghangatkan ruangan sekaligus menjadi alat penerangan. Pada waktu makan malam seluruh anggota berkumpul di perapian. Ruangan lain yang ada pada rumah nouka ini ada dua ruangan yang terletak paling dekat douma digunakan sebagai tempat melakukan kegiatan harian para penghuni rumah.

2. Machiya ( rumah di perkotaan ) Rumah Machiya berbeda dengan rumah nouka dengan ciri khas utama mempunyai bentuk empat persegi panjang hal ini dikarenakan terbatasnya luas tanah di daerah perkotaan.

Di dalam rumah machiya terdapat ruang utama yang disebut dengan omoya. Di Belakang ruang utama omoya tersebut dibangun ruang untuk menyimpan harta benda milik keluarga (douzo/kura). Selain itu untuk menyimpan harta benda keluarga mereka juga membangun zashiki yang diletakan terpisah dari ruangan utama. Untuk memasuki ruangan ini dibuatkan pintu pada ruang doma menuju ke pekarangan belakang.

Ciri khas lain dari rumah machiya ini dibangun tiga baris ruang di sekitar doma. Ruang yang paling dekat dengan ruas jalan disebut dengan mise yang bisa diganakan untuk berjualan. Ruang yang terletak di bagian tengah digunakan sebagai kantor dan sebagai ruang untuk menerima tamu dari luar. Adapun ruang yang dibangun di bagian belakang di buat menghadap taman dan tertutup. Ruang ini dibuat menyerupai zashiki lengkap dengan tokonoma yang berfungsi sebagai tempat melakukan kegiatan harian dari anggota rumah tangga tersebut.

Karena terbatasnya luas tanah di perkotaan maka rumah machiya sering dibangun tingkat dua dan di lantai dua dibangun ruang yang disebut dengan zushi, Ruang ini terbagi menjadi dua bagian yaitu bagian yang dekat dengan jalan mempunyai langit -langit rendah sebagai gudang. Bagian kedua adalah bagian belakang yang dipergunakan sebagai kamar tidur.

\subsection{Karakteristik Rumah Minka}

Meskipun setiap wilayah di Jepang mempunyai rumah minka dengan ciri khas masing-masing wilayah tersebut namun secara umum rumah minka di Jepang mempunyai karakter yang sama sebagai berikut.

1. Arsitek rumah Minka di Jepang memiliki sifat ringan dan halus. 
Sifat ringan dan halus merupakan ciri khas utama rumah minka. Setiap elemen dalam rumah Minka dibuat, dibentuk dan diolah dengan halus dan menonjolkan sisi kesederhanaan dan minimalis.

2. Konstruksi kayu lebih menonjol dan diolah sangat halus dengan bentuk-bentuk lengkung dan kesederhanaan.

3. Bentuk bangunan diatur dalam simetris yang seimbang

4. Menjaga keharmonisan antara arsitektur tanaman, naturalis dengan desain bangunan.

5. Menonjolkan kesederhanaan bentuk dan garis

6. Pada pengolahan taman dibuat senatural mungkin seperti tanpa sentuhan tangan manusia

7. Menonjolkan minimalis ruang

8. Sedikit penggunaan warna lebih menonjolkan warna politur dan lak

Adapun jenis bahan bangunan ynag digunakan dalam pembangunan rumah Minka antara lain meliputi: a) Balok kayu besar untuk tiang utama rumah dan rangkarangka penting dari kerangka rumah. b). Kayu yang digunakan untuk dinding, lantai, langit-langit dan bubungan atap. c). Bambu yang digunakan untuk melapisis tempattempat kososng diantara dinding kayu dan setelah itu dilapisis dengan tanah liat untuk dijadikan dinding rata.d) Tanah liat yang dibakar untuk dijadikan genteng. e). Rumput jenis tertentu yang digunakan sebagai atap. f) Jerami yang dianyam untuk dijadikan tikar kasar yang disebut denagn mushiro, dan tikar khas Jepang yang disebut denagn tatami yang digelar di atas tikar kasar. G) Batu-batu yang digunakan hanya untuk fondasi rumah, tidak untuk dinding.

\subsection{Eleman Khas Rumah Minka}

Selain mempunyai karakteristik unik dalam arsitekturnya, rumah minka Jepang juga mempunyai elemen khas yang unik yang membedakan dengan rumah tradisional yang lainnya. Berikut penjelasan mengenai elemen khas yang dimiliki rumah Minka Jepang.

1. Bagian depan rumah lubang untuk masuk dipasangi dua lapis pintu . Lapisan pintu bagian dalam shouji berupa pintu geser, yang berlubanglubang dan ditutupi kertas-kertas. Sedangkan pintu lapis bagian depan berupa pintu kayu yang kokoh.

2. Bagian dalam rumah dibagi menjadi ruangan-ruangan yang dipisahkan dengan pintu geser yang berkisi-kisi. Pintu - pintu pemisah ruangan ini secara keseluruhan disebut dengan tategu. Kisi-kisis ini ditutupi kertas-kertas tebal tembus cahaya yang disebut dengan fusuma.

3. Adanya doma, yaitu salah satu bagian dalam rumah yang lantainya terbuat dari tanah liat yang sudah dikeraskan. Pada doma dipasang semacam oven untuk memasak yang terbuat dari tanah liat (kamado). Selain itu, di lantai ini juga diletakkan perapian terbuka irori untuk membakar kayu pemanas ruangan.

4. Atap Rumah minka sering dibuat curam, dan biasanya terbuat dari ilalang (kayabukiyane), sirap (itabukiyane) dan genteng ( kawarabuki yane).

Adapun atap minka dapat dikelompokan menjadi tiga bentuk yaitu:

a) Kirizuma, merupakan jenis atap yang paling sederhana yang berbentuk segitiga (gable roof)

b) Yasumune, merupakan jenis atap yang mempunyai pinggang (hipped roof). Atap ini merupakanperkembangan dari kirizuma, karena pada keduasisi sampingnya yang lain ditambah dengan atap miring dan bubungannya tidak berbentuk lancip melainkan rata. 
c) Irimoya, merupakan jenis atap berbentuk tiga segi dengan atap tambahan yang berbentuk agak miring di sekitarnya, sehingga ruang dalam rumah menjadi luas

5. Pada rumah yang atapnya terbuat dari genteng keramik, genteng juga dipasang sampai ke ujung bubungan, dan untuk menghias puncak bubungan dipasang genteng yang ujungnya berbentuk kepala raksasa yang disebut onigawara. Pada rumah yang beratap rumput juga dipasangi hiasan pada kedua sudutnyayang disebut munekazari.

6. Pada rumah yang atapnya terbuat dari genteng keramik, genteng juga dipasang sampai ke ujung bubungan, dan untuk menghias puncak bubungan dipasang genteng yang ujungnya berbentuk kepala raksasa yang disebut onigawara. Pada rumah yang beratap rumput juga dipasangi hiasan pada kedua sudutnyayang disebut munekazari

\subsection{Tata Ruang Rumah Minka}

Secara umum Tata ruang rumah minka Jepang dapat dijelaskna sebagai berikut 1.Pintu masuk

Seperti pada umumnya rumah di Jepang, pada rumah minka pun terdapat genkan yaitu koridor tempat penghuni rumah atau tamu masuk dan melepas sandal mereka. Memang orang Jepang mempunyai kebiasaan menanggalkan alas kaki berupa sendal atau sepatu pada saat akan memasuki rumah. di genkan juga disediakan sebuah rak atau lemari untuk menyimpan sepatu yang disebut dengan getabako. Penghuni rumah atau tamau yang berkunjung meletakan sepatu dengan rapih di getabaki tersebut sebelum memasuki rumah. Di genkan juga disediakan tempat menyimpan payung . Berikut gambar genkan

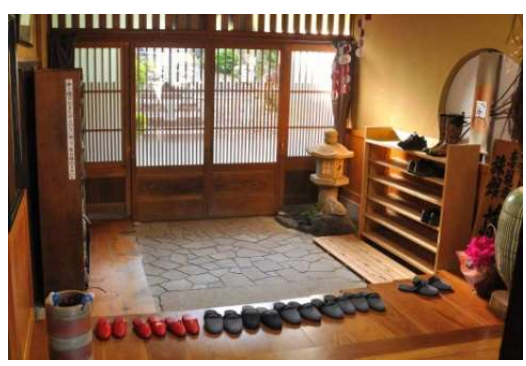

Gambar 3. Genkan

2.Ruang keluarga, ruang kerja dan kamar tidur

Pada rumah minka terdapat ruang yang disebut dengan washitsu yaitu ruang unik dan serba guna yang beralaskan tikar tatami. Ruang washitsu ini bisa digunakan sebagai ruang keluarga, ruang belajar dan waktu malam bisa juga digunakan sebagai ruang tidur.

Berikut gambar washitsu

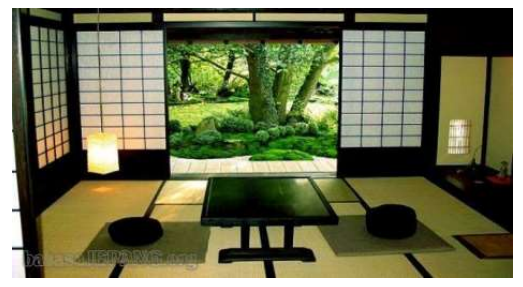

Gambar 4 washitsu

\section{Lantai}

Lantai pada rumah minka umumnya menggunakan tatami sejenis tikar tebal yang dibuat dari jerami sudah dipakai di Jepang sejak sekitar 600 tahun yang lalu. Berikut gambar tatami

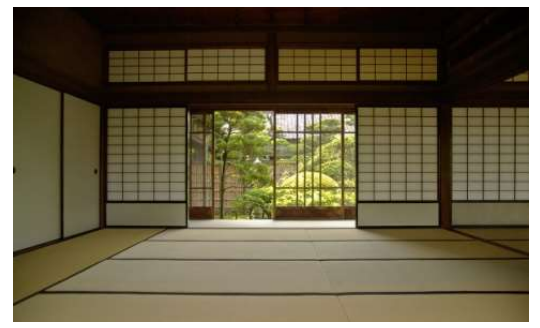

Gambar 5. tatami

\section{Lorong}

Pada minka terdapat juga lorong yang disebut dengan rouka yaitu lorong yang 
berada di pinggir rumah, biasanya berlantai kayu. Berikut adalah gambar rouka

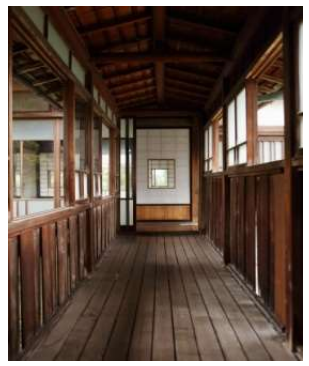

Gambar 6 rouka

\section{Dapur}

Pada minka terdapat dua jenis dapur yang dugunakan untuk tempat memasak. (daidokoro) . Yang pertama dapur yang di dalamnya terdapat tungku biasa dan yang kedua tungku yang digantung. Kedua jenis tungku tersebut menggunakan kayu bakar . Berikut gambar dapur rumah minka Jepang

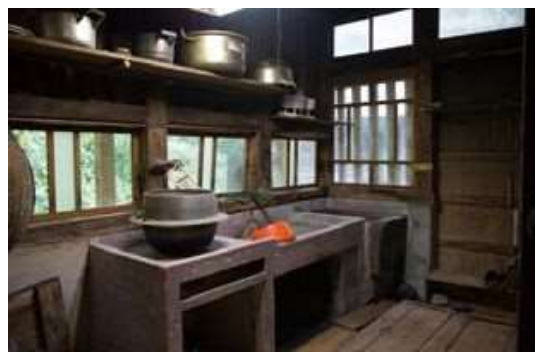

Gambar 7 daidokoro

\section{Ruang sembahyang}

Pada minka terdapat tokonoma yaitu suatu ruangan yang berukuran lebih kecil dari ruangan yang ada dalam rumah. Letaknya berada di dalam kamar dengan posisinya lebih tinggi dari beberapa inchi dari lantai tatami. Alasan dibuat lebih tinggi dari lantai sebuah ruangan karena karena lantai atas pada ruangan pemujaan ini diilustrasikan sebagai dewa, sedangkan lantai bawah diilustrasikan sebagai manusia.

Berikut gambar tokonoma

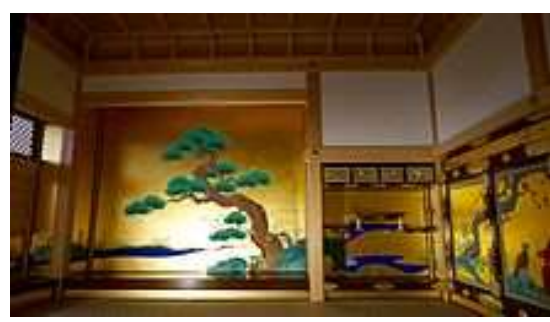

Gambar 7 tokonoma

7.kloset

Kloset rumah minka Jepang berbeda dengan kloset rumah Jepang pada umumnya. Rumah minka Jepang menggunakan kloset washiki yaitu kloset jongkok yang dikenal sebagai kloset Asia. Kebanyakan kloset jongkok di Jepang menggunakan porselen. Para pengguna toilet di Jepang kebalikan dari Indonesia dimana mereka menghadap ke dinding di belakang toilet. Kloset jongkok di bagi menjadi dua jenis, kloset yang berada di permukaan lantai dan kloset yang berada di bagian lantai yang ditinggikan lebih mudah digunakan untuk buang air kecil sambil berdiri.

Berikut gambar kolset rumah minka

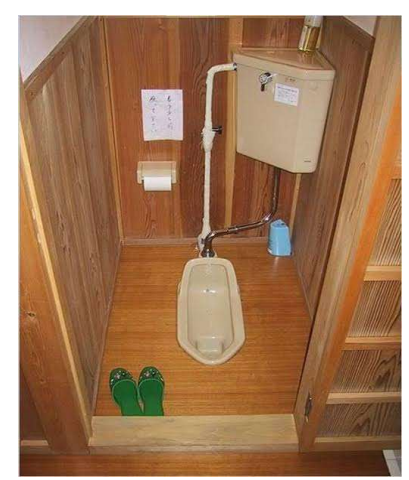

Gambar 8. Kloset minka

\section{Ventilasi}

Pada mink aterdapat runma yaitu jendela kecil di atas pintu yang memiliki ukuran yang berada di atas dinding dan digunakan diantara shouji dan plafon untuk memberikan sirkulasi udara dan cahaya .

Berikut gambar ventilasi rumah minka 
Kiryoku, Volume 3 No 42019

e-ISSN: 2581-0960 p-ISSN: 2599-0497

Tersedia online di http://ejournal.undip.ac.id/index.php/kiryoku

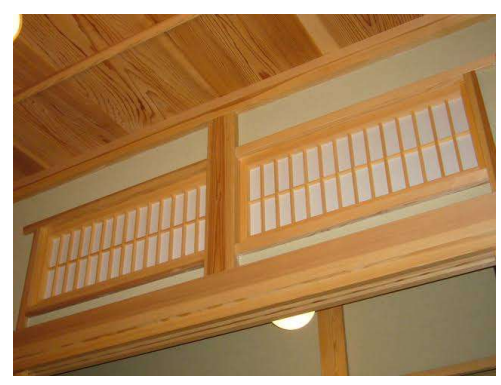

Gambar 9 ranma house. Japan: The Internasional

House of Japan,Inc

Sumber Elektronik

http://en.wikipedia.org/wiki/housing in ja pan diunduh pada tanggal 7 Desember 2019

http://misakiyuuki.blogspot.com/2011/06/ minka-rumah-tradisional-jepang.html diunduh pada tanggal 1 Desember 2019

\section{PENUTUP}

Jepang merupakan negara yang memelihara budaya tradisional dalam berbagai macam bidang. Arsitektur rumah minka merupakan salah satu budaya yang masih dijaga sampai sekarang sehingga di setiap wilayah di Jepang masih bisa ditemui rumah bergaya minka. Bahkan rumah modern di Jepang pun memasukan beberapa elemen rumah minka sehingga akan terasa perpaduan gaya modern dengan gaya tradisional minka.

Rumah minka mempunyai banyak ciri khas yang menjadi keunikan tersendiri yang tidak dimiliki oleh jenis rumah tradisional lainnya. Salah satu hal yang paling menonjol dari keunikan rumah tradisional minka Jepang adalah terdapat pada elemen-elemen khas dalam denah rumah yang tidak terdapat pada rumah tradisional yang lainnya. Keunikan tersebut menjadi daya tarik dari rumah minka sehingga keberadaan rumah minka tetap terjaga samapai sekarang.

\section{REFERENSI}

Anonim. (2008). Metode dan Teknik Tradisional dalam Arsitektur Jepang. Antariksa.

Anonim, Sejarah Arsitektur Jepang, Tim Jurusan Teknik Arsitektur.

Anonim. (1998). The Kodansha Bilingual Encyclopedia of Japan, Tokyo: Kodansha Internasional

Pratiwi, Aulia Rachma. Perbandingan Rumah Tradisional Minka di Jepang dan Rumah Tradisional Gapura Candi . Bali. (2016). Universitas Diponegoro Takeshi. Nakagawa. (2005). The Japanese 